\title{
Capital Trading, Stock Trading, and the Inflation Tax on Equity* $^{*}$
}

\author{
Ralph Chami ${ }^{\dagger}$ \\ IMF Institute \\ Thomas F. Cosimano ${ }^{\ddagger}$ \\ University of Notre Dame \\ and \\ Connel Fullenkamp ${ }^{\S}$ \\ Duke University
}

May 1998; Revision October 2000

\begin{abstract}
A market for used capital goods, or financial instruments that represent the ownership of the used capital goods, induces inflation taxes on wealth and on the nominal income flows they provide. This paper explicitly introduces trading in either used capital goods or financial instruments into the standard stochastic growth model with money and production. These two monetary economies are equivalent. The value of the firm is equal to the firm's capital stock divided by inflation. The resulting asset-pricing conditions indicate that the effect of inflation on asset returns differs from the effects found in the literature by the addition of a significant wealth tax.
\end{abstract}

\footnotetext{
${ }^{*}$ We would like to thank Scott Baier, William Brock, Paul Evans, Matt Higgins, Pam Labadie, Eric Leeper, Len Mirman, and Jim Peterson, as well as seminar participants at The Cleveland Federal Reserve Bank, Indiana University, The International Monetary Fund, Purdue University and Western Michigan University for comments on a previous version. Tom Cosimano received financial support from the Center for Research in Financial Services Industry at The University of Notre Dame.

${ }^{\dagger}$ IS 3-1908, International Monetary Fund, Washington D.C. 20431. E-mail: rchami@imf.org

${ }^{\ddagger}$ Department of Finance and Business Economics, University of Notre Dame, Notre Dame, IN 46556.E-mail: thomas.f.cosimano.1@nd.edu Phone: 219-631-5178 Fax: 219-631-5255

${ }^{\S}$ Department of Economics, Box 90097, Duke University, Durham NC 27708. Email: cfullenk@econ.duke.edu
} 


\section{Introduction}

It is well known that whenever a transaction is subject to a cash-in-advance constraint, the government can capture part of the real value of the goods or services being exchanged by imposing an inflation tax. Inflation taxes create real distortions that establish a link between monetary policy and real economic activity. The inflation taxes modeled in this way include taxes on consumption and on dividend (capital rental) payments. Up to now, the inflation taxes introduced into models have had only limited success in matching the impact of monetary policy on real activity that is present in the data.

Part of the reason for the poor performance of cash-in-advance models is that they have overlooked a significant source of transactions associated with the trade in used capital. A right associated with ownership of an asset is the right to sell it at a market price. In early monetary models, however, individuals were not given this right, because a capital goods market was not present. Once a market for the asset is established, owners can exercise their rights to exchange assets at a market price, creating the possibility of an inflation tax on this wealth. Since the total value of capital goods used by business is quite large, it is likely that the inflation tax on capital trading has a significant effect on aggregate economic activity.

Of course, most capital trading is accomplished through the exchange of equity shares. The stock market can also be thought of as a cash-in-advance market for trading existing capital goods. In this market, certificates representing ownership claims on particular sets of capital goods are exchanged among households, for cash payments. Therefore, an economy with a stock market should be subject to an inflation tax on traded capital identical to the one described above, with the accompanying effects on real quantities. Well specified stock markets, however, have likewise been omitted from previous monetary growth models.

In this paper, we introduce a cash-in-advance market for existing capital to a standard growth model with money. Giving the households the right to trade existing capital complicates their wealth allocation decision and introduces richer dynamics than are present in previous cash-in-advance models. An inflation tax on existing capital goods affects both the 
household's demand for existing capital as well as its investment in new capital goods. We show in simulations that these effects are significant.

We then demonstrate that the standard growth model with cash-in-advance trading of used capital goods is equivalent to a model in which households own and trade shares of stock while the firms own capital goods and make the investment decision in the economy. This equivalence property provides a link between growth models and realistic asset-pricing models and is an important contribution of the paper. For example, the financial version of this model implies that all traded assets issued by the firm are subject to the inflation tax and therefore that financial assets provide an important path through which monetary policy affects the real economy. ${ }^{1}$

In the next section, we introduce a used capital goods market into a traditional cash-inadvance economy with production. In Section 3 we replace the used capital goods market with a stock market and demonstrate that the two monetary economies yield the same dynamic behavior. In Section 4 we simulate the model. Responses of consumption and the capital stock to inflation shocks in the model with trading in used capital are over 40 times larger than the responses generated by the growth model without used capital trading. In addition, the inflation tax on equity is 45 times larger than that in the traditional cash-in-advance model without a used capital market. Section 5 discusses why the inflation tax is substantially bigger in the presence of a used capital goods or a stock market. Section 6 finds that the equivalence between monetary economies with either a used capital goods market or a stock market carries over to more complex economies including shopping time models and alternative forms of financing used by the firm. The last section concludes the paper.

\section{An Economy with A Used capital goods market}

The model is a combination of Lucas' (1982) and Lucas and Stokey's (1987) cash-in-advance (CIA) model with Brock and Mirman's (1972) stochastic growth model. Preferences take the form of a CRRA utility function, while production is represented by a neoclassical production

\footnotetext{
${ }^{1}$ Recently, Sharpe (1999) has documented that expected inflation has a significant effect on stock returns.
} 
function with partial depreciation of the capital stock. The timing convention is similar to Sargent (1987) and Cooley and Hansen (1989), rather than to Svensson (1985) or Hodrick, Kocherlakota and Lucas (1991), in that asset decisions are made before goods are purchased. A single representative firm and representative household comprise the private economy.

\subsection{Timing, Technology, and Stochastic Processes}

With regard to timing, we follow the convention established by Sargent (1987), in which there are three sessions to each time period. At the beginning of the period, the gross rate of money growth and the shock to productivity for time period $t$ are revealed to all. In the first session, the following events take place: the government prints additional money and imposes a lumpsum tax on households; households reallocate their assets and supply labor inelastically to the firms; firms lease the capital from the households; and firms combine capital and labor to produce output. In the second session, firms sell output to the households as consumption and investment goods. In the third session, the firms pay wages and rental payments to the households. Chart 1 illustrates the timing of this model.

Output is produced according to the production function

$$
Y_{t}=F\left(\theta_{t} L_{t}, K_{t}\right)
$$

where $\theta_{t}$ is the temporary shock to productivity, $L_{t}$ is inelastically supplied labor, and $K_{t}$ is the quantity of capital. ${ }^{2}$ The production function is assumed to be continuously differentiable, homogenous of degree one, and increasing as well as concave in labor and capital. In addition, the production function satisfies the Inada conditions.

Next period's real capital stock is a function of the capital stock last period and last period's real investment in new capital, $I_{t}$ :

$$
K_{t+1}=(1-\delta) K_{t}+I_{t}
$$

where $\delta$ is the depreciation rate.

\footnotetext{
${ }^{2}$ In an earlier version, we also included a deterministic trend in production, as is done in King, Plosser, and Rebelo (1988). This does not affect our result, so it is omitted for the sake of simplicity.
} 
Assume the firm operates in a competitive environment in which it rents the capital from the households for the nominal rental payment $R_{t}$. The factor payments for capital and labor satisfy

$$
R_{t}=P_{t} F_{2}\left(\theta_{t} L_{t}, K_{t}\right)
$$

and

$$
W_{t}=P_{t} \theta_{t} F_{1}\left(\theta_{t} L_{t}, K_{t}\right)
$$

where $W_{t}$ is the nominal wage rate and $P_{t}$ is the price level. Consequently, these factor payments exhaust the sales of the firm in the second session and are paid to the household in the third session.

Money enters the economy when the government collects a real lump sum tax $\left(\mathcal{T}_{t}\right)$ on the household and simultaneously distributes additional money $\left(M_{t}-M_{t-1}\right)$ to it. Since the change in the money stock is assumed to be an exogenous stochastic process, the tax collections of the government must satisfy the government budget constraint

$$
\mathcal{T}_{t}=-\frac{M_{t}-M_{t-1}}{P_{t}}
$$

The stochastic shocks to the model are the growth rate of money and the temporary productivity shock. Following Cooley and Hansen (1995), money growth $\mu_{t+1}=M_{t+1} / M_{t}$ and the productivity shock are assumed to follow the stationary Markov processes

$$
\begin{aligned}
\mu_{t+1} & =\Psi_{10} \mu_{t}^{\Psi_{11}} \exp \left[u_{t+1}\right] \\
\theta_{t+1} & =\theta_{t}^{\Psi_{22}} \exp \left[\epsilon_{t+1}\right]
\end{aligned}
$$

We assume that the innovations in money growth, $u_{t+1}$, and productivity, $\epsilon_{t+1}$, are mean-zero, i.i.d. random variables drawn from bounded sets. ${ }^{3}$

\subsection{Household's Budget and Balance-Sheet Constraints}

A helpful way to understand the structure of the model is to derive the various constraints faced by the household in the order that they arise. In Session 1, the household decides how

\footnotetext{
${ }^{3}$ See Altuğ and Labadie (1994, pp 144 and 224) for a discussion of this assumption.
} 
to allocate its wealth. The consumer begins the period with given nominal wealth $\left(\mathcal{W}_{t}\right)$, which consists of currency carried over from the previous time period $\left(M_{t-1}\right)$ and new money balances printed by the government $\left(M_{t}-M_{t-1}\right)$. In addition to nominal wealth, the household also owns capital stock, which is composed of two parts. One part comes from the used capital that the household purchased the previous period, $k_{t-1}^{d}$. This capital has been in existence since the beginning of the previous period, and has therefore depreciated to $(1-\delta) k_{t-1}^{d} \cdot{ }^{4}$ This capital may be sold in the asset market at the price $Q_{t}$ per unit. ${ }^{5}$ The second part of the capital stock includes the capital goods obtained through investment last period. These capital goods have not depreciated, being just now ready for use or sale. The household paid $P_{t-1} I_{t-1}$ for these capital goods last period, but they can now be sold at the current market price of capital, $Q_{t}$. Thus, the nominal value of the household capital held at the beginning of the asset market is

$$
Q_{t} k_{t}^{s}=Q_{t}\left[(1-\delta) k_{t-1}^{d}+I_{t-1}\right]
$$

Total initial wealth is the sum of nominal wealth and the nominal value of capital. Given this initial wealth, the consumer decides how much money $\left(M_{t}^{p}\right)$ and capital $\left(k_{t}^{d}\right)$ it would like to purchase, and pays the real lump sum tax $\left(\mathcal{T}_{t}\right)$ owed to the government. The consumer's purchases of assets are therefore subject to the constraint

$$
Q_{t} k_{t}^{d}+M_{t}^{p} \leq \mathcal{W}_{t}+Q_{t} k_{t}^{s}-P_{t} \mathcal{T}_{t}
$$

In the second session, the consumer purchases output in the amount $P_{t} C_{t}$ subject to the CIA constraint

$$
P_{t} C_{t} \leq M_{t}^{p}
$$

We will henceforth concern ourselves with equilibria where the CIA constraint is binding, such that (9) holds with equality. ${ }^{6}$ In addition to purchasing consumption goods, the household also chooses the level of investment in new capital goods during this session. The cost of the

\footnotetext{
${ }^{4}$ Following tradition we use big $\mathrm{K}$ for aggregate capital and little $\mathrm{k}$ for individual holdings of the capital stock.

${ }^{5}$ See Altuğ and Labadie (1994, pp 179 - 185) and Altuğ (1993) for a discussion of how a used capital market impacts real economies.

${ }^{6}$ See Sargent (1987, pp. 161), and Cooley and Hansen (1989 p. 736).
} 
investment is $P_{t} I_{t}$. But investment goods are not subject to a CIA constraint, being paid for in the third session.

In the final session, the firm pays wages and rental fees to the consumer, so that the consumer enters the next time period with nominal wealth given by

$$
\mathcal{W}_{t+1}=M_{t}^{p}-P_{t} C_{t}-P_{t} I_{t}+W_{t} L_{t}^{s}+R_{t} k_{t}^{d}
$$

where $L_{t}^{s}$ is the quantity of labor chosen by the household.

If we update (7) one period and add it to nominal wealth, we obtain an expression for the nominal value of total wealth at the beginning of period $t+1$ that gives some insight into the household's decision:

$$
\mathcal{W}_{t+1}+Q_{t+1} k_{t+1}^{s}=M_{t}^{p}-P_{t} C_{t}+\left(Q_{t+1}-P_{t}\right) I_{t}+W_{t} L_{t}^{s}+R_{t} k_{t}^{d}+Q_{t+1}(1-\delta) k_{t}^{d}
$$

This equation shows that investment in new capital at time $t$ is subject to the possibility of a capital gain or loss based on the difference between the price of new capital at time $t$ and the price of old capital at time $t+1$. This consideration affects the requirements for equilibrium, as we shall see below.

\subsection{The Consumer Optimization Problem}

The consumer chooses the amounts of money, used capital, investment, and consumption in each time period to maximize

$$
E_{t} \sum_{j=0}^{\infty} \beta^{j} \frac{C_{t+j}^{1-\gamma}}{1-\gamma}
$$

subject to the constraints (7), (8), (9), and (10). Labor is supplied inelastically such that $0 \leq L_{t}^{s} \leq 1$. Here $\gamma$ is the constant relative risk aversion parameter and $\beta$ is the consumer's subjective rate of discount. $E_{t}(z)$ is the household's expectation of $z$ conditional on its information at time $t$, which includes the current monetary and productivity shocks.

Although the consumer chooses money, used capital, new capital goods and consumption during the period, we focus on the purchase of used and new capital. It is clear that used and new capital goods are two distinct assets from the point of view of the households, since the 
timing of payments and receipts are distinct. In the case of used capital, if a household keeps the capital then it gives up the real value of the capital good in the secondary market at the beginning of time $t$. The household then receives the rental payment at the end of time period $t$ and has the ability to sell the capital good net of depreciation during the asset market in time $t+1$. On the other hand, investment at time $t$ in new capital reduces total nominal wealth at time $t+1$, following (10). This investment does not return a rental payment until the end of time $t+1$ and the household can sell the capital good net of depreciation in the secondary market for capital at time $t+2$. Thus, the payments and receipts for new capital expenditures are delayed by one period relative to used capital goods.

The demand functions for new and used capital exhibit the tradeoffs and timing just described. The optimal demand for used capital goods is ${ }^{7}$

$$
\frac{Q_{t}}{P_{t}}=E_{t}\left[\frac{m r s_{t+1}}{\Pi_{t+1}}\left(F_{2}\left(\theta_{t} L_{t}, K_{t}\right)+(1-\delta) \frac{Q_{t+1}}{P_{t}}\right)\right]
$$

where $m r s_{t+1} \equiv \beta\left(\frac{C_{t+1}}{C_{t}}\right)^{-\gamma}$ is the intertemporal marginal rate of substitution, and $\Pi_{t+1} \equiv \frac{P_{t+1}}{P_{t}}$ is the inflation rate. The optimal demand for new capital goods is

$$
E_{t}\left[\frac{m r s_{t+1}}{\Pi_{t+1}}\right]=E_{t}\left[m r s_{t+1} \frac{m r s_{t+2}}{\Pi_{t+2}}\left(F_{2}\left(\theta_{t+1} L_{t+1}, K_{t+1}\right)+(1-\delta) \frac{Q_{t+2}}{P_{t+1}}\right)\right] .
$$

Although new and used capital are distinct assets, they are related by the capital accumulation equation. In particular, the choice of investment determines the supply of real capital in the subsequent period. But up to this point, we have not forced any agreement or consistency on the two choices, in the sense that the optimal choice of investment at time $t$ would imply a supply of capital stock for the household that it finds optimal to hold at time $t+1$. From the point of view of the individual household, which may trade in the capital market during time $t+1$, such agreement is not necessary. From the perspective of the entire economy, however, such agreement may be needed for equilibrium.

\footnotetext{
${ }^{7}$ A guide to the proper derivation of equations (12) and (13) is available from the authors.
} 


\subsection{Competitive Equilibrium}

An equilibrium in this economy consists of a set of initial conditions for capital stock, $K_{1}>0$, money stock $M_{0}$ and consumption, $C_{0}>0 ;^{8}$ exogenous stochastic processes for $\left(\mu_{t}, \theta_{t}\right)_{t=1}^{\infty}$ which satisfy (6); endogenous stochastic processes for the quantity variables $\left(M_{t}^{p}, k_{t}^{d}, k_{t}^{s}, \mathcal{T}_{t}, C_{t}, K_{t+1}\right.$, $\left.Y_{t}, I_{t}, L_{t}\right)_{t=1}^{\infty} ;$ and endogenous stochastic processes for prices $\left(P_{t}, Q_{t}, R_{t}, W_{t}\right)_{t=1}^{\infty}$ such that the following conditions hold:

1. Government Solvency: The government budget constraint (5) is satisfied for all $t>0$.

2. Household Optimizing Behavior: Given the stochastic processes for prices and the initial conditions, the stochastic processes for money, used capital, investment and consumption solve the consumer's problem (11) subject to the constraints $(7),(8),(9)$, and (10) for all $t>0$.

3. Firm Optimizing Behavior: The rental and labor decisions of the firm solve the firm's optimal conditions (3) and (4) for all $t>0$.

4. Market Clearing: The endogenous stochastic processes for money, labor, consumption, investment, and output satisfy the market clearing conditions for the money market $\left(M_{t}=M_{t}^{p}\right)$, the labor market $\left(L_{t}=L^{s}\right)$ and the goods market $\left(Y_{t}=C_{t}+I_{t}\right)$, such that these conditions are binding for all $t>0$.

5. Capital Market Equilibrium: The supply, $k_{t}^{s}$, and demand, $k_{t}^{d}$, for used capital goods are equal and the households' holding of capital, $k_{t}$, equals the aggregate amount of capital, $K_{t}$, for all $t>0$.

The extra condition (5) for equilibrium in the economy is the final important difference between this model and previous work on monetary economies. ${ }^{9}$ In previous models of monetary

\footnotetext{
${ }^{8}$ The last two conditions ensure that there is an initial price level, $P_{0}$.

${ }^{9}$ The model we present as the standard model is very similar to Carlstrom and Fuerst's (1995) model without portfolio rigidities as well as to Cooley and Hansen's (1995) model with no credit good. These standard models are comparable to Abel's (1985) perfect foresight model when the household owns the capital stock.
} 
economies with production, the household owns the capital stock but does not have the option to sell the used capital goods in the asset market. In such cases the optimal condition (12) is not present, since the price of used capital, $Q_{t}$, is not germane. Previous models do have a first order condition for new capital (investment) like (13), but the distinction between $Q_{t+2}$ and $P_{t+1}$ is not relevant, since there is no possibility of selling the new capital in the future used capital goods market.

The differences mentioned above have significant consequences for general equilibrium. First, with the presence of the used capital goods market it now becomes necessary to specify an equilibrium condition for the used capital market. But finding equilibrium in this market is nontrivial, because of the interconnection between the used and new capital goods market. The demand for new capital effectively determines the supply of used capital one period hence. But as mentioned above, the household uses different criteria to select the optimal levels of investment in period $t$ and used capital in period $t+1$. Therefore, the household will not necessarily choose to supply the amount of used capital that it demands, which would imply excess demand or supply in the used capital market. The second consequence comes in the goods market. Since the household is now choosing both consumption and investment, it is possible for excess demand or supply to exist in the goods market as a result of conditions affecting the demand for new capital. In particular, it was demonstrated above that there is a possibility of capital gains and losses on new capital goods. If a capital gain on investment were expected by the household, its demand for investment goods would be infinite and there would be excess demand in the goods market.

These consequences have two practical implications for solving the model. First, equilibrium requires that if either one of equations (12) or (13) is satisfied, this must imply that the other is also satisfied. Second, the solution must be consistent with no expected capital gains or losses on investment. We will demonstrate that these two requirements are equivalent in equilibrium. Therefore, we can begin solving the model by satisfying these requirements. 


\subsection{Solving for Competitive Equilibrium}

We now turn to solving for the competitive equilibrium of the monetary economy. Our solution procedure is to establish a condition which reconciles the household's decisions for used and new capital goods. Once this condition is established, the proof of the existence of the competitive equilibrium follows a standard technique. This reconciliation is complicated since the used capital decision at time $t$ compares payments between $t$ and $t+1$ while the investment decision at time $t$ compares payments between $t+1$ and $t+2$. It turns out that these two conditions will be consistent under the following Theorem.

Theorem 1 If the household chooses the optimal level of used capital for each period based on condition (12) when the price of used capital goods, $Q_{t}$ is equal to last period's price level, $P_{t-1}$, then the optimal level of new capital goods (13) will be guaranteed.

\section{Proof:}

Equilibrium between the used and new capital market occurs when the demand for used capital determined by (12) is in agreement with the household's investment decision (13) which determines the supply in the used capital goods market. We start with (12) and determine the conditions under which it agrees with (13).

First, increase the time period by 1 in equation (12) so that

$$
\frac{Q_{t+1}}{P_{t+1}}=E_{t+1}\left[\frac{m r s_{t+2}}{\Pi_{t+2}}\left(F_{2}\left(\theta_{t+1} L_{t+1}, K_{t+1}\right)+(1-\delta) \frac{Q_{t+2}}{P_{t+1}}\right)\right] .
$$

Multiplying both sides of the above equation by $m r s_{t+1}$, and using the law of iterated expectations yields

$$
E_{t}\left[m r s_{t+1} \frac{Q_{t+1}}{P_{t+1}}\right]=E_{t}\left[m r s_{t+1} \frac{m r s_{t+2}}{\Pi_{t+2}}\left(F_{2}\left(\theta_{t+1} L_{t+1}, K_{t+1}\right)+(1-\delta) \frac{Q_{t+2}}{P_{t+1}}\right)\right] .
$$

A comparison of this condition with the optimal investment decision of the household (13) reveals that the two decisions concur when $Q_{t+1}=P_{t}$ for all $t$.

One way to understand the condition in the theorem is to realize that $P_{t}$ is effectively the supply price of used capital at time $t+1$, since investment at time $\mathrm{t}$, determined by (13), is 
the marginal contribution to the supply of used capital at time $t+1$. The supply price must equal the forward demand price in equilibrium, since the investor always anticipates that the forward demand price will satisfy (12) at time $t+1$. The Theorem effectively imposes the law of one price on the two Euler equations. This is sufficient to guarantee that one Euler condition implies the other because, as the Proof shows, the conditions are essentially identical except for the one-period lag.

Note that the Theorem also implies that there are no capital gains or losses on investment. This is the second requirement that the solution must satisfy, which was discussed above.

The Theorem implies a rigidity in the price of used capital goods in that the forward price of used capital, $Q_{t+1}$ does not respond to information at time $t+1$. The real price of used capital, $\frac{Q_{t+1}}{P_{t+1}}=\frac{1}{\Pi_{t+1}}$, does adjust to developments at time $t+1$. For example, an increase in productivity at time $t+1$ would lead to lower inflation, so that the real price of used capital increases. Thus, the equilibrium in the used and new capital markets is achieved through the adjustment of the real price of used capital rather than its nominal price.

Now we show how we use Theorem 1 to collapse the conditions for a competitive equilibrium down to two conditions that can be simulated. Theorem 1 implies that if the household's Euler equation for used capital is satisfied when $Q_{t}=P_{t-1}$, then the household's Euler equation (13) for investment is also satisfied. Therefore we start with the household's Euler equation, (12) and substitute for the equilibrium price of used capital goods:

$$
\frac{1}{\Pi_{t}}=E_{t}\left[\frac{m r s_{t+1}}{\Pi_{t+1}}\left(F_{2}\left(\theta_{t} L_{t}, K_{t}\right)+(1-\delta)\right)\right] .
$$

The next step is to substitute out the inflation terms. But before proceeding to that step, we can use this relation to gain some insight into the distortion in this economy that occurs because of inflation. Following Coleman(1996), the above equation is identical to a real economy in which the income from capital is subject to a stochastic inflation tax. If we move $\Pi_{t}$ to the right-hand side of the equation, we see that the Euler equation is identical to the one from a real economy except that a stochastic tax is applied to both the rental income and the value of pre-existing capital. We can interpret the right-hand side as the after-tax proceeds from 
capital, where the stochastic tax rate is $1-\frac{\Pi t}{\Pi_{t+1}}=-\left(\frac{Q_{t+1}}{P_{t+1}}-\frac{Q_{t}}{P_{t}}\right) / \frac{Q_{t}}{P_{t}}$. Thus, the stochastic tax rate is equal to the percentage decrease in the real price of used capital. This result implies that an acceleration in inflation leads to a higher tax rate, since the real price of used capital falls. This tax effect influences the dynamics of the economy, since the inflation rate is endogenous.

The equilibrium condition in the money market, together with (9), allows us to substitute out the price (inflation) terms and express the stochastic tax rate as $1-\frac{\mu_{t}}{\mu_{t+1}} \frac{C_{t+1}}{C_{t}} \frac{C_{t-1}}{C_{t}}$. Substituting this expression for the inflation tax into the equilibrium relation yields

$$
\frac{C_{t}}{\mu_{t} C_{t-1}}=E_{t}\left[m r s_{t+1} \frac{C_{t+1}}{\mu_{t+1} C_{t}}\left(F_{2}\left(\theta_{t} h_{t}, L_{t}\right)+(1-\delta)\right)\right]
$$

Finally, we substitute the definition of $m r s_{t+1}$, obtaining

$$
\frac{C_{t}\left(C_{t}\right)^{-\gamma}}{\mu_{t} C_{t-1}}=\beta E_{t}\left[\frac{C_{t+1}\left(C_{t+1}\right)^{-\gamma}}{\mu_{t+1} C_{t}}\left(F_{2}\left(\theta_{t} L_{t}, K_{t}\right)+(1-\delta)\right)\right] .
$$

Equation (14) is a function of $K_{t}, C_{t}$ and exogenous variables. To obtain this equation, we have used all the equilibrium conditions except for the goods market equilibrium and the equation of motion for the aggregate capital stock. ${ }^{10}$ We take these remaining equations in the system to obtain the second equation in the two-equation system that is used to solve for equilibrium:

$$
C_{t}=F\left(\theta_{t} L_{t}, K_{t}\right)-\left(K_{t+1}-(1-\delta) K_{t}\right)
$$

Equations (14) and (15) yield a third order difference equation in the capital stock. Below we present simulations of these conditions using the LQ procedure. The solution to these conditions will represent the competitive equilibrium when the household is allowed to trade the used capital stock.

\subsection{Comparison With Previous Work}

To see how the competitive equilibrium implied by our model differs from that implied in traditional models where the household does not trade in used capital goods, we briefly present a representative of this standard model and make key comparisons. The model we present as

\footnotetext{
${ }^{10}$ It is not necessary to simulate (13), since the Theorem shows that this condition will be satisfied when (14) is true.
} 
the standard model is very similar to Carlstrom and Fuerst's (1995) model without portfolio rigidities, as well as to Cooley and Hansen's (1995) model with no credit good. ${ }^{11}$

The traditional model is identical to the model presented above except that the household is not allowed to trade used capital goods. This restriction means that condition (12) is no longer present in the model, while the distinction between the price of used and new capital is no longer relevant. The definition of competitive equilibrium is identical to the one in Section 2.4 without the capital market equilibrium condition 5 .

We can reduce the traditional model down to two conditions,

$$
E_{t}\left[\frac{C_{t+1}\left(C_{t+1}\right)^{-\gamma}}{\mu_{t+1} C_{t}}\right]=\beta E_{t}\left[\frac{C_{t+2}\left(C_{t+2}\right)^{-\gamma}}{\mu_{t+2} C_{t+1}}\left(F_{2}\left(\theta_{t+1} L_{t+1}, K_{t+1}\right)+(1-\delta)\right)\right]
$$

and

$$
C_{t}=F\left(\theta_{t} L_{t}, K_{t}\right)-\left(K_{t+1}-(1-\delta) K_{t}\right)
$$

The economy with a used capital goods market, which is governed by (14) and (15), will behave differently from the traditional model, described by (16) and (17). The economy with a used capital goods market is more restrictive than the traditional economy. An examination of (14) and (16) reveals that if (14) is true for every time period, then (16) is automatically satisfied. ${ }^{12}$ The source of this difference is the variation in the timing of payments from used capital goods versus new capital goods. In the traditional economy, there is only investment in new capital goods at time $t$, which transfers payments between time $t+1$ and $t+2$. This helps to explain why (16) compares the expected loss in time $t+1$ with the expected gain in time $t+2$ to determine the economy wide capital stock at time $t+1$. On the other hand, the economy with a used capital market adds an asset that transfers payments from time $t$ to $t+1$, so that an extra condition, (12), must also be satisfied. Theorem 1 shows that the two methods of acquiring capital are made consistent by a law of one price, $Q_{t}=P_{t-1}$ for all $t$. This law of one price introduces a price rigidity into the economy.

\footnotetext{
${ }^{11}$ The LQ simulations of these standard models are comparable to Abel's (1985) perfect foresight model, in which new capital is specified as a credit good and consumption as a cash (in advance) good, since these simulations satisfy the certainty equivalence property.

${ }^{12}$ Increase the time period in (14) by one and apply the conditional expectation to obtain (16)
} 
This price rigidity changes the dynamics of the real economy since it influences the stochastic tax rate imposed on capital through a change in the real price of used capital goods. ${ }^{13}$ In a model without a used capital goods market, the stochastic tax rate is dependent on the prices from $P_{t}$ to $P_{t+2}$, which are all allowed to adjust to the change in monetary policy. In the economy with a used capital goods market, the stochastic tax rate and the real price of used capital depend on the prices $P_{t-1}$ to $P_{t+1}$. But the price $P_{t-1}$ is pinned down by history, so that all the adjustment of the tax rate to monetary policy must be through the prices $P_{t}$ and $P_{t+1}$. Thus, the dynamic behavior of the economy with a used capital goods market is different, because the law of one price associated with the additional market induces a different timing of tax payments.

\section{An Economy with A Stock Market}

In this section we introduce an explicit stock market, which we demonstrate is equivalent to the economy with a market for used capital goods. The timing, technology, stochastic processes and preferences are the same as the used capital goods model. The household replaces the ownership of capital with stock certificates, which promise the dividends earned by the firm. The firm is now in control of the capital good and decides whether to purchase new investment. In the following we lay out the distinct elements of the model with stock ownership.

\subsection{Budget and Balance-Sheet Constraints}

In addition to the technology constraints it faces, the firm must allocate its profits between dividends and retained earnings. The retained earnings are used to finance the firm's investment. The firm earns profits at time $t$ given by $P R_{t}=P_{t} F\left(\theta_{t} L_{t}, K_{t}\right)-W_{t} L_{t}$. These profits are either paid out to the shareholders as dividends or retained by the firm, so that $P R_{t}=R E_{t}+D_{t} S_{t}$, where $R E$ represents retained earnings, $D$ is nominal dividends, and $S=1$ is the number of shares. The firm finances investment with retained earnings: $P_{t} I_{t}=R E_{t}$. Therefore, nominal

\footnotetext{
${ }^{13}$ This explains why the necessary conditioning information in (14) is $C_{t}$ and $C_{t-1}$ while it is only $C_{t}$ in (16).
} 
dividends satisfy

$$
D_{t}=P_{t}\left[Y_{t}-I_{t}\right]-W_{t} L_{t}
$$

The derivation of equation (18) shows the first important difference between the stock market and the used capital goods economy. The firm's constraint reflects the separation of the firm from the household. Instead of having the quantity of investment dictated to it by the household, the firm chooses the share of profits it will reinvest in itself and the share it will pay out as dividends. As equation (18) shows, the shareholders in this model are residual claimants, since dividends are the revenues left over after wages and investment funds have been paid out.

Money enters the economy the same way as in the used capital goods model and is subject to the government budget constraint (5). The consumer faces a separate constraint in each session during a time interval. The consumer begins the period with given nominal wealth $\left(\mathcal{W}_{t}\right)$, which consists of the following: the stocks of the firm purchased in the previous time period $\left(S_{t-1}\right)$, which pay nominal dividends $\left(D_{t-1}\right)$; currency carried over from the previous time period $\left(M_{t-1}\right)$; and new money balances printed by the government $\left(M_{t}-M_{t-1}\right)$. Given this initial wealth, the consumer decides how much money $\left(M_{t}^{p}\right)$ and stock $\left(S_{t}\right)$ to purchase, and pays the real lump sum tax $\left(\mathcal{T}_{t}\right)$ owed to the government. The consumer's purchases of assets are carried out subject to the constraint

$$
\frac{P_{t}^{s} S_{t}}{P_{t}}+\frac{M_{t}^{p}}{P_{t}} \leq \frac{\mathcal{W}_{t}}{P_{t}}-\mathcal{T}_{t}
$$

where $P_{t}^{s}$ is the price of a share of stock at time $t$.

In the second session, the consumer purchases output in the amount $P_{t} C_{t}$ subject to the CIA constraint (9). Thus, the total sales of the firm to the consumer are $P_{t}\left[Y_{t}-I_{t}\right]=P_{t} C_{t} \leq M_{t}^{p}$.

In the final session, the firm pays wages and dividends to the consumer, so that the consumer enters the next time period with real wealth

$$
\frac{\mathcal{W}_{t+1}}{P_{t+1}}=\frac{R_{t+1}^{s} P_{t}^{s}}{P_{t+1}} S_{t}+\frac{M_{t}^{p}-P_{t} C_{t}}{P_{t+1}}+\frac{W_{t} L_{t}^{s}}{P_{t+1}}
$$

where

$$
R_{t+1}^{s} \equiv \frac{P_{t+1}^{s}+D_{t}}{P_{t}^{s}}
$$


is the ex post nominal gross return on stock.

\subsection{The Consumer and Firm's Optimization Problems}

The consumer chooses the amount of money, stocks and consumption in each time period to maximize (11) subject to the constraints (9), (19), and (20). Although the consumer chooses money, stocks, and goods during the period, we focus only on the stock purchase decision. The optimal demand for stocks is

$$
1=E_{t}\left[m r s_{t+1} \frac{R_{t+1}^{s}}{\Pi_{t+1}}\right] .
$$

The consumer must pay the ownership value of the firm this period in exchange for the ownership value of the firm next period plus the dividend payment next period. The transfer of payments is similar to the used capital goods market (12) except that the payoff is in terms of the gross return on stocks rather than the rental payment and proceed from the sale of used capital next period. Thus, the consumer's demand for used capital is similar to the demand for equity.

Using the definition of nominal stock returns (21) in the optimal condition (22) allows us to solve (22) forward for the consumer's valuation of stock price,

$$
\frac{P_{t}^{s}}{P_{t}}=E_{t} \sum_{j=0}^{\infty}\left\{\left[\prod_{i=0}^{j} m r s_{t+i+1}\right] \frac{D_{t+j}}{P_{t+j+1}}\right\},
$$

which is the discounted value of all future dividends. The consumer's intertemporal marginal rate of substitution is the stochastic discount factor used by the investor.

Next we turn to the firm's decision. The firm is the owner of the capital stock, which it finances with retained earnings. The firm cannot pay nominal dividends until current goods are sold so that dividends produced this period are not available until next period. The firm chooses labor and capital to maximize the discounted value of current and future real dividends. The firm's stochastic discount factor, $d i s_{t+i}, i=1, \cdots, \infty$ is exogenously given to the firm. This stochastic discount factor is determined in equilibrium.

The choice of discount factor for the firm is an important feature of this model. Having separate discount factors for the firm and the household creates the separation between the 
household and the corporation. When the firm and the household are identical, then the firm knows the household's discount factor and it is appropriate for the firm and the household to use the same discount factor. But if the household and the firm are distinct entities, then the firm does not necessarily know the household's marginal rate of substitution. Thus the firm should have a discount factor that differs from the household's discount factor. We specify the firm's discount factor as an endogenous variable whose value is determined in equilibrium.

The firm exists for the benefit of the household shareholders. Therefore we assume that the firm's objective is to maximize the discounted value of all future dividends that are distributed to the shareholders. ${ }^{14}$ We refer to this objective as the value of the firm. Thus, the firm's present value maximization problem is

$$
V_{t}^{F} \equiv \max _{K_{t+1}, L_{t}} E_{t} \sum_{j=0}^{\infty}\left\{\left[\prod_{i=0}^{j} d i s_{t+i+1}\right] \frac{D_{t+j}}{P_{t+j+1}}\right\},
$$

subject to (1), (2) and (18).

The firm's optimal labor decision satisfies the condition (4), so that the real wage is equal to the marginal product of labor. The firm's optimal investment decision satisfies the condition ${ }^{15}$

$$
E_{t}\left[\frac{d i s_{t+1}}{\Pi_{t+1}}\right]=E_{t}\left[d i s_{t+1} \frac{d i s_{t+2}}{\Pi_{t+2}}\left(F_{2}\left(\theta_{t+1} L_{t+1}, K_{t+1}\right)+(1-\delta)\right)\right] .
$$

Denote by $\operatorname{mri}_{t+1} \equiv F_{2}\left(\theta_{t+1} L_{t+1}, K_{t+1}\right)+1-\delta$ the firm's marginal return on investment.

This investment decision by the firm is similar to the investment decision, (13), by the household in the used capital goods economy in that the timing of payments are identical. The distinction between the price of used, $Q_{t+2}$, and new capital, $P_{t+1}$, is no longer present since the firm does not trade its used capital.

\footnotetext{
${ }^{14}$ This implies that the firm may try to learn about the household's preferences in order to choose the correct discount rate. For the sake of simplicity, and because this is an equilibrium model, we do not introduce firm learning about household time preferences.

${ }^{15}$ See Cochrane (1991) for the derivation.
} 


\subsection{Competitive Equilibrium in The Stock Market Economy}

The definition of equilibrium in the stock market economy is similar for the first four conditions to the definition in the used capital goods economy. The only essential difference is

5. No Arbitrage Condition: The real value of firm's equity is equal to the value of the firm

$\left(\frac{P_{t}^{s}}{P_{t}} S_{t}=V_{t}^{F}\right)$ and the number of shares is constant $\left(S_{t}=1\right)$ for all $t>0$.

The new condition 5 for equilibrium in the economy is the final important difference between the stock market and used capital goods economy. Condition 5 reflects the fact that there is a nontrivial equity market in this model. The household rebalances its wealth portfolio each period, so its demand for the stock must be equal to the supply of equity each period. At the same time, the firm is investing each period and changing the value of the physical assets owned by the shareholders. The equity market reconciles the investment decision of the firm with the financial investment decision of the household, i.e., the firm's value and equity value. Market clearing in the stock market is equivalent to the absence of arbitrage opportunities between these two values.

\subsection{Solving for Competitive Equilibrium in the Stock Market Economy}

Now we consider the solution of the competitive equilibrium for the economy with a stock market. We proceed as in the case of the used capital goods economy. First we reconcile the financial decision of the household with the investment decision of the firm, using a new version of Theorem 1. Then we use this Theorem to simplify the model to the same two equations (14) and (15) as in the used capital goods economy. Thus, the stock market economy yields the same competitive equilibrium as the used capital goods economy.

In the stock market economy, the household's demand for stocks (22) must be reconciled with the firm's decision to invest in new capital goods (25) when we recognize the source of the stock dividend payments is the real economic activity of the firm, i.e., equation (18).

Theorem 2 The conditions for equilibrium in the stock market are (1) the firm's stock price at any time $t$ is $P_{t}^{s}=P_{t-1} K_{t}$, and (2) the firm's stochastic discount factor at any time $t$ is 
equal to the consumer's intertemporal marginal rate of substitution plus an i.i.d. shock with mean zero and uncorrelated across time, $e_{t}$, i.e., dis $s_{t}=m r s_{t}+e_{t} \cdot{ }^{16}$

Proof: See the Appendix.

Theorem 2 also has an important Corollary. Following Restoy and Rockinger (1994), we have

\section{Corollary $1 R_{t}^{s}=\Pi_{t} m r i_{t}$}

Proof: See the Appendix.

When the production technology displays constant returns to scale, and when the firm has access to complete contingent claims markets, Altuğ and Labadie (1994) and Restoy and Rockinger (1994) prove in a production based asset pricing model that the firm's value function is equal to the capital stock. Moreover, Restoy and Rockinger (1994) prove that the real stock return is equal to the same period's marginal return on investment. Our result is in nominal terms because of the possibility of inflation, while the one period delay is due to the delay in the payment of nominal dividends.

One implication of Theorem 2 that needs to be addressed is that the stock return is known at time $t$. This is simply an artifact of the information structure we choose for this model. In particular, it is a direct consequence of including time $t$ 's dividend payment in the household's time $t$ information set, which enables the household to infer the productivity and monetary shocks. We choose this specification for clarity and convenience. When we make the more realistic assumption that the period $t$ dividend is not observed by the household until time $t+1$, this does make the stock return random, but it also makes the stock return depend on a shock to the marginal productivity of labor. This additional term complicates the model without altering Theorem 2 or any of the relationships between inflation and stock returns discussed below. Since our purpose is to highlight the effect of inflation on stock returns,

\footnotetext{
${ }^{16}$ In an earlier version of the paper we allowed for a bubble, which complicated the analysis. The implications were identical to those found in Diba and Grossman (1988).
} 
we chose the information structure that yielded the simpler (and hence more transparent) expressions linking stock returns and inflation.

Corollary 1 leads immediately to the result

Theorem 3 The competitive equilibrium in the used capital goods and stock market economies are identical.

If Corollary 1 is used to substitute the nominal return into (22), then we obtain (14). This equation and the resource constraint (15) are the two conditions for equilibrium in the stock market economy. Thus, both the used capital goods and stock market economies are characterized by the same equations of motion for consumption and the capital stock.

\section{Simulation}

Our strategy is to simulate our model and calculate the responses of the variables of the model to a given monetary shock. We then compare these impulse responses to those generated by an identically calibrated growth model in which households own the capital stock but do not trade used capital. For ease of notation, we refer to our specification in which households trade used capital as the "trading" model, and the standard growth model with no trading of used capital as the "no-trading" model.

The simulation proceeds as follows. For each model, we choose steady-state parameter values. We solve the capital accumulation equation for each model, using approximation techniques, and generate a time series of capital by choosing the series of shocks to the model. Then we use the equations of the model to generate time series of the other variables.

The parameters of the model were chosen both to be consistent with other work and to keep the models simple. Most of the parameters of the models were taken from Cooley and Hansen $^{17}(1995)$, while some were taken directly from or implied by equations in Campbell (1994). Others were chosen in order to obtain a zero-growth steady state. For example, the

\footnotetext{
${ }^{17}$ The parameter values were chosen to be the following: $\alpha=.40 ; \delta=.012 ; h^{s}=.31 ; \beta=.991 ; \gamma=5 ; \ln \left(\psi_{10}\right)$ $=.0066 ; \psi_{11}=.491 ; \sigma_{u}=.0089 ; \ln \left(\psi_{20}\right)=.00 ; \psi_{22}=.95 ; \sigma_{\epsilon}=.007$. Thomas Cooley provided the data to reproduce these parameters.
} 
population growth rate was set to zero, and the subjective rate of time preference was chosen to ensure zero steady-state consumption growth.

The capital accumulation equation for each model was found using an approach based on Christiano's (1990) LQ method. We apply this method to equations (14) and (15) from our model. As a representative of the standard model, we simulate (16) and (17) to represent Cooley and Hansen's (1995) model. ${ }^{18}$

Once the capital accumulation equations were derived, we performed the following simulation exercise. Starting from identical steady states $^{19}$, each model was shocked with a two standard deviation increase in money growth, which serves as an inflation shock. The responses of the capital stock, the value of the firm, consumption, and real stock returns were calculated. The graphs of the impulse-response functions are given in Figures 1-3.

In the figures, the impact of the additional inflation tax appears as increased responses to inflation shocks relative to the responses generated by the standard no-trading model. Figure 1 graphs the response of the value of the firm to the monetary shock. The Figure shows that in the first period after the monetary shock, the value of the firm falls further when households are allowed to trade used capital. The relative sizes of the drop are $2.3 \%$ of value with trading and $1.7 \%$ with no trading.

Turning to real stock returns in Figure 2, we see a much more dramatic difference in the reaction to a monetary shock across the two different models. Stock returns exhibit a stronger initial reaction to the monetary shock when used capital is traded. From a steady-state return of $1.48 \%$ per quarter, stock returns fall by 56 basis points when households trade used capital, while they fall only 1.2 basis points under no trading. The difference in return volatility following the shock is also pronounced. The mean squared distance between the stock return and its steady state value over the first 20 periods after the shock, which is a measure of

\footnotetext{
${ }^{18}$ In Carlstrom and Fuerst (1995) the stochastic case without portfolio rigidities, equations (10) thru (12) can be reduced to (16) and (17). Similarly, the equilibrium conditions for Cooley and Hansen's (p.198, 1995) model can be reduced to (16) and (17) when there is no credit good in their model.

${ }^{19}$ It turns out that given the same parameters, both models imply the same steady state. This occurs because it is the uncertainty over the value of household assets that distinguishes the trading model from the no-trading model. In a steady state, there is essentially no uncertainty over the value of household assets. Abel (1985) shows that money is super neutral in this case.
} 
the volatility created in the stock return as a result of the monetary shock, is .0017 when households trade used capital but only .000036 when households do not trade used capital. These differences show that stock returns exhibit far more sensitivity to a money (inflation) shock when households are able to trade used capital goods.

Another significant difference between the models that is clearly shown in Figure 2 is the amount of negative correlation induced in stock returns. For the first 20 periods after the shock, the first-order autocorrelation of the return is - .79 when trade in used capital is allowed and -.46 when households do not trade used capital. And when the entire sample is used, the first-order autocorrelations become -.20 and .98 , respectively. Not only is the negative autocorrelation in returns far larger when used capital is traded, but the negative autocorrelation also persists in the data over a longer horizon. This result appears to be a direct result of the tax on wealth introduced when the capital stock is traded. As mentioned below, the wealth tax arises from a change in inflation, which reduces the capital gain in one period but increases it the next period. This wealth tax creates the oscillation in the return that is visible in Figure 2.

The monetary shock also has effects on the levels of consumption, which are graphed in Figure 3. Again, trading in used capital is associated with a greater response to the monetary shock. Consumption falls over half a percent in the first period after the monetary shock in the trading model, while consumption declines by only .012\% in the no-trading model. The larger drop in consumption is at least partially due to the larger drop in the value of the firm depicted in Figure 1. It is also related to the volatility induced in stock returns by the monetary shock, following a permanent income hypothesis argument. The increase in return volatility reduces the household's estimate of its permanent income, which in turn reduces consumption. The fall in consumption raises the level of capital in both models, but only by very small amounts. Capital rises by .01\% when firms own the capital, but only by $.0002 \%$ when households own the capital stock. Nevertheless, the used capital trading model generates a much larger response to the monetary shock, relative to the standard model with no trading of used capital. 


\section{The Inflation Tax on Wealth}

To gain an intuitive understanding of the differences between the models, it is useful to think of our result in terms of the inflation taxes that are present in the model. Every monetary model features some distortion that is caused by inflation. Since money plays several roles in the economy, however, several different approaches to modeling the inflation tax on returns are possible.

Marshall (1992), for example, focuses on money's role as an additional asset that is a potential substitute for other securities. In this view, inflation taxes the total return to money, which includes the transactions services provided by money. When the after-tax return to money falls, this reduces the return to other assets, to the extent that they are good substitutes for money.

The approach of Labadie (1989) utilizes the role of money as a unit of account in that the presence of money in an economy drives a wedge between real and nominal values. This wedge creates opportunities for monetary authorities to tax the value of all nominally-denominated incomes and assets. Therefore, in Labadie's model, inflation affects stock returns by taxing dividends as well as the purchasing power of money.

Many papers that document the effects of inflation on stock returns include only this tax, including both anticipated inflation models following Stockman (1981) and stochastic inflation models such as Cooley and Hansen $(1989,1995)^{20}$.

In our model, we find three separate inflation taxes that affect stock returns. The first two are the purchasing power tax and the dividend tax from the exchange-economy literature. ${ }^{21}$ The third inflation tax stems from the household's ability to trade capital.

We have shown above that the nominal price of capital is sticky: at time $t+1, Q_{t+1}$ must be equal to the previous period's price level, $P_{t}$. This is a requirement for equilibrium in the

\footnotetext{
${ }^{20}$ Lucas (1982), Lucas and Stokey (1987), Boyle and Young (1988), Labadie (1989), Cooley and Hansen (1989), Boyle (1990), Hodrick, Kocherlakota and Lucas (1991), Giovannini and Labadie (1991), and Boyle and Peterson (1995) also study this effect.

${ }^{21}$ Mackinnon (1987) adds production to the Stockman (1981) model and separates ownership of capital from ownership of stocks. He also shows the presence of a dividend tax in addition to the purchasing power tax in a perfect foresight cash-in-advance model.
} 
capital market. Because of this price rigidity, the real value of the capital may be easily taxed by raising the price level from period $t$ to period $t+1$, which lowers the real price of capital. In period $t+1$, one unit of capital has declined in value from one unit of consumption to $\frac{1}{\Pi_{t+1}}<1$ units. The change in relative value is part of the government's income from the tax. This tax is similar to the dividend tax in Labadie (1989) but is distinct because it is a tax on the entire value of the capital stock rather than the flow of dividends from that stock. In other words, the distinction between the taxes is akin to that between income and property taxes.

Although we cannot show analytically the distortion caused by the inflation tax on wealth, we can give some intuition. The wealth tax affects the balance between the costs and benefits of buying new and used capital, which is the basis of the demand curves (12) and (13). Recall that the household trades off the benefit of receiving rental payments against the cost of giving up the real value of the capital. Therefore the additional tax on the real value of capital present in the trading model leads to changes in the equilibrium allocation of capital. In addition, the need to reconcile the new and used markets for capital imparts a different dynamic response to inflation taxes.

We now show how the above result increases the effect of inflation on stock returns. One way to see this is to rewrite the Euler equation for the optimal financial investment decision using the formula for the real stock price in Theorem 2. Substituting the real stock price from Condition (1) of Theorem 2 into the household's Euler equation for stocks (22) yields

$$
1=\left[m r s_{t+1}\left(\frac{D_{t}}{P_{t} \frac{\Pi_{t+1}}{\Pi_{t}}}+\frac{K_{t+1}}{\frac{\Pi_{t+1}}{\Pi_{t}}}\right)\left(\frac{1}{K_{t}}\right)\right] .
$$

In (26), the term $\mathrm{mrs}_{t+1}$ is, in Cochrane's (1991) terminology, the stochastic discount factor used to price the asset. The next term in brackets shows two of the three inflation taxes on equity returns described above (the inflation tax on purchasing power is also present, but affects the stock return indirectly).

First, the term $\frac{D_{t}}{P_{t}}$ represents the inflation tax on dividends, which is present in most asset pricing models with money. In exchange economy models such as Labadie (1989), this is the 
only direct inflation tax on stock returns. But in our model, there is an additional inflation tax on dividends, and this tax is captured by the change in inflation. This same tax impinges on the capital stock as well. The equation shows that the entire capital stock of the firm is taxed because of the change in the real value of capital.

The response of asset prices to the presence of the additional inflation tax on wealth is not obvious from the above equation. As discussed above, the nature of the distortion captured in the model is more complex than a simple reduction in return due to an additional tax. The inflation tax on wealth taxes the capital stock of the firm, while the dividend tax falls on the household's cash flows. Thus, one way to look at the effect of the additional tax is that it upsets the balance between the stock price and the value of the firm. In other words, inflation disturbs the no-arbitrage condition that must hold in equilibrium.

\section{Robustness}

The equivalence between economies with a stock market and a used capital goods market caries over to more complex economic models. In our 1999 IMF working paper, we show that the results in Theorems 2 and 3 carry over to Marshall's (1992) shopping time model. The difference in the analysis is a change in the functional form of the consumer's marginal rate of substitution.

The effects of inflation on stock returns in the shopping time model will be similar to those in the CIA model: inflation and stock returns are negatively correlated. On the other hand, the shopping time model implies that the velocity of money will change in response to changes in short-term interest rates, while velocity is fixed in the CIA model. This creates a positive correlation between stock returns and the quantity of money in the shopping time model, ${ }^{22}$ in contrast to the negative correlation between money and stock returns in the CIA model. Recently, Thorbecke (1997) and Patelis (1997) have further documented the positive correlation between money and stock returns empirically.

We also examined the Modigliani Miller property that the competitive equilibrium in the

\footnotetext{
${ }^{22}$ See Marshall (1992).
} 
economy will not change, if the firm finances a fraction of its investments with bonds rather than stocks. We allowed the firm to issue commercial paper at the beginning of each time period. $^{23}$ The commercial paper is paid off at the end of the period. At the beginning of each period the firm sells $a_{t}$ in nominally denominated commercial paper, which promises to pay back $R_{t}^{a} a_{t}$ dollars. At the same time the firm pays dividends on the equity of the firm. In this case Theorem 2 and Corollary 1 are replaced by ${ }^{24}$

Theorem 4 The conditions for equilibrium in the stock and bond markets are (1) the firm's real stock price at any time $t$ is $\frac{P_{t}^{s}}{P_{t}}=\frac{K_{t}}{\Pi_{t}}-\frac{a_{t}}{P_{t}}$, and (2) the firm's stochastic discount factor at any time $t$ is equal to the consumer's intertemporal marginal rate of substitution plus an i.i.d. shock with mean zero and zero correlation across time, $e_{t}$, i.e., dis $s_{t}=m r s_{t}+e_{t}, E\left(e_{t}\right)=0$, $E\left(e_{t} e_{t+I}\right)=0, I \neq 0$.

Corollary $2 q_{t} R_{t+1}^{s}+\left(1-q_{t}\right) R_{t}^{a}=\Pi_{t}$ mri $_{t}$, where $q_{t}=\frac{P_{t}^{s}}{P_{t}^{s}+a_{t}}$

The main implication of Theorem 4 is that the conditions for equilibrium in the competitive economy collapse to the same two conditions (14) and (15). Thus, the equilibrium behavior of capital and consumption will be the same regardless of whether the firm issues commercial paper in addition to equity. Consequently, the real value of the firm will be identical as well. On the other hand, the financing decision of the firm does determine how the value of the firm is allocated to equity and bond holders. In Corollary 2, the nominal value of the marginal return on investment is now allocated to a return on equity and a return on commercial paper based on the market value of equity relative to the total market value of the firm.

In summary, the property first stated by Modigliani and Miller (1958), that the value of the firm is independent of the type of financing used by the corporation, is replicated in monetary economies. On the other hand, the production based asset pricing model developed by Cochrane (1991) is modified in the presence of debt financing by the firm. Based on Corollary 2, the

\footnotetext{
${ }^{23}$ We call this bond commercial paper because it is short-term, unsecured corporate debt that is usually paid off by issuing new paper. These characteristics correspond closely to those of commercial paper.

${ }^{24}$ Our IMF working paper contains the model and proof using the more general capital accumulation function of Restoy and Rockinger (1994).
} 
nominal value of the marginal return is equal to the weighted cost of capital when the firm has debt financing rather than the firm's stock return alone.

\section{Conclusion}

The punch line in many economic models is that ownership affects behavior. This model also has that implication. Ownership gives an individual the legal right to sell an asset at the current market price. This ownership right can be in the form of direct or indirect control depending upon whether there is a stock market. In either case the competitive equilibrium of the monetary economy is influenced by a wealth tax when inflation accelerates. In particular, we show that the existence of ownership rights for physical capital goods in the economy significantly affects the behavior of stock returns. Stock returns, the value of the firm, and consumption display a dramatically higher level of sensitivity to inflation shocks when ownership rights are present. The reason why something as simple as ownership rights has such a significant impact on stock returns is because it creates a new nominally denominated asset-used capital or stock certificates-whose value is related to the capital stock. The existence of ownership rights creates a new channel through which the inflation tax can affect stock returns. This additional channel is the monetary authority's ability to tax the entire value of the capital stock during each period. Because the value of the capital stock is quite large, this tax is large. The inflation tax on wealth also creates arbitrage opportunities between the ownership value and the leasing value of financial instruments. Removal of these arbitrage opportunities demands significant adjustments in both real and nominal variables.

In addition, our results also suggest that introducing ownership rights may also help the standard growth model match other characteristics of equity returns that have been documented in data but not predicted well by theory. For example, our simulations show that the capital trading model does a better job of inducing the negative autocorrelation observed in stock returns than the standard growth model without ownership rights. In a related point, monetary shocks in our model induce a higher level of return volatility than they do in the standard model. This may help shed some light on the so-called "excess volatility" problem in stock 
returns. Investigating whether the model can better explain these additional characteristics of stock returns is a task for further research. 


\section{Appendix}

\section{Proof of Theorem 2:}

Equilibrium in the stock market occurs when the demand for stocks determined by (22) is in agreement with the firm's investment decision (25) so that the equity market clears, satisfying equilibrium condition 5. We start with (22) and determine the conditions under which it agrees with (25).

First, increase the time period by 1 in equation (22) so that

$$
P_{t+1}^{s}=E_{t+1}\left\{\frac{m r s_{t+2}}{\Pi_{t+2}}\left(P_{t+2}^{s}+D_{t+1}\right)\right\} .
$$

Multiplying both sides of the above equation by $\frac{m r s_{t+1}}{P_{t+1}}$, and using the law of iterated expectations yields

$$
E_{t}\left\{\frac{m r s_{t+1}}{P_{t+1}} P_{t+1}^{s}\right\}=E_{t}\left\{\frac{m r s_{t+1}}{P_{t+1}} \frac{m r s_{t+2}}{\Pi_{t+2}}\left(P_{t+2}^{s}+D_{t+1}\right)\right\}
$$

We now need an expression for dividends. The firm's optimal labor decision (4) together with Euler's Theorem applied to (1) implies that $P_{t} Y_{t}-W_{t} L_{t}=P_{t} F_{2}\left(\theta_{t} L_{t}, K_{t}\right) K_{t}$. Also the capital accumulation condition (2) allows us to solve for investment $P_{t} I_{t}=P_{t}\left[K_{t+1}-(1-\delta) K_{t}\right]$ so that dividends (18) are given by

$$
D_{t}=P_{t} F_{2}\left(\theta_{t} L_{t}, K_{t}\right) K_{t}-P_{t}\left[K_{t+1}-(1-\delta) K_{t}\right]
$$

Substituting (28) updated one period into (27) yields

$$
E_{t}\left\{m r s_{t+1} \frac{P_{t+1}^{s}}{P_{t+1}}\right\}=\begin{gathered}
E_{t}\left\{m r s_{t+1} m r s_{t+2} \frac{P_{t+2}^{s}}{P_{t+2}}+\right. \\
\left.m r s_{t+1} \frac{m r s_{t+2}}{\Pi_{t+2}}\left[F_{2}\left(\theta_{t+1} L_{t+1}, K_{t+1}\right) K_{t+1}-K_{t+2}+(1-\delta) K_{t+1}\right]\right\}
\end{gathered}
$$

Finally, regroup terms in $(29)$ such that

$$
\begin{gathered}
E_{t}\left\{m r s_{t+1} \frac{P_{t+1}^{s}}{P_{t+1}}\right\}=E_{t}\left\{m r s_{t+1} m r s_{t+2}\left[\frac{P_{t+2}^{s}}{P_{t+2}}-\frac{K_{t+2}}{\Pi_{t+2}}\right]\right\}+ \\
E_{t}\left\{m r s_{t+1} \frac{m r s_{t+2}}{\Pi_{t+2}}\left[F_{2}\left(\theta_{t+1} L_{t+1}, K_{t+1}\right) K_{t+1}+(1-\delta) K_{t+1}\right]\right\} .
\end{gathered} .
$$

A comparison of the investor's optimal behavior (30) with the optimal investment decision of the firm (25) reveals that the two decisions concur when Conditions (1) and (2) of the 
Theorem are satisfied. Substitution of (23) and (24) into condition 5 demonstrates that the no arbitrage condition is also satisfied.

\section{Proof of Corollary 1:}

The definition of the marginal return on investment implies

$$
\Pi_{t} m r i_{t}=\Pi_{t}\left[\left(F_{2}\left(\theta_{t}, L_{t}, K_{t}\right) K_{t}+(1-\delta) K_{t}\right) \frac{1}{K_{t}}\right] .
$$

Using the expression for real dividends (28) in (31) yields

$$
\Pi_{t} m r i_{t}=\frac{\Pi_{t}}{K_{t}}\left[\frac{D_{t}}{P_{t}}+K_{t+1}\right] .
$$

Finally, using Condition (1) from Theorem 2, that $\frac{P_{t}^{s}}{P_{t}}=\frac{K_{t}}{\Pi_{t}}$ yields

$$
\Pi_{t} m r i_{t}=\Pi_{t+1} \frac{\frac{D_{t}}{P_{t+1}}+\frac{P_{t+1}^{s}}{P_{t+1}}}{\frac{P_{t}^{s}}{P_{t}}}=R_{t+1}^{s} .
$$

\section{Proof of Equality Between Used Capital Goods and Stock Market Economies:}

Now we show how to use Conditions (1) and (2) of Theorem 2 to collapse the five conditions for equilibrium down to the same two conditions in the used capital goods economy. Condition (2) of Theorem 2 implies that if the household Euler equation is satisfied, then the firm's Euler equation (25) is also satisfied. Therefore we start with the household's Euler equation, (22):

$$
\frac{P_{t}^{s}}{P_{t}}=E_{t}\left[m r s_{t+1}\left(\frac{P_{t+1}^{s}}{P_{t+1}}+\frac{D_{t}}{P_{t+1}}\right)\right]
$$

We use condition (1) from Theorem 2 to substitute $\frac{K_{t}}{\Pi_{t}}$ for $\frac{P_{t}^{s}}{P_{t}}$ on both sides, obtaining

$$
\frac{K_{t}}{\Pi_{t}}=E_{t}\left[m r s_{t+1}\left(\frac{K_{t+1}}{\Pi_{t+1}}+\frac{D_{t}}{P_{t+1}}\right)\right] .
$$

Again, using the Theorem to eliminate $\frac{P_{t}^{s}}{P_{t}}$ implies that condition 5 is also satisfied.

We now proceed to solve for the fundamental solution to (35). We use the equilibrium equation in the money market together with (9) to find $P_{t}=M_{t} / C_{t}$, so that $\Pi_{t}$ and $P_{t}$ are functions of $C_{t}$ and $M_{t}$, which yields

$$
\frac{K_{t} C_{t}}{\mu_{t} C_{t-1}}=E_{t}\left[m r s_{t+1}\left(\frac{K_{t+1} C_{t+1}}{\mu_{t+1} C_{t}}+\frac{D_{t} C_{t+1}}{M_{t+1}}\right)\right] .
$$


Now we use equation (28) and the expression for the price level to replace $D_{t}$ with a function of $K_{t}, C_{t}$ and $M_{t}$ :

$$
\frac{K_{t} C_{t}}{\mu_{t} C_{t-1}}=E_{t}\left[m r s_{t+1} \frac{C_{t+1}}{\mu_{t+1} C_{t}}\left(K_{t+1}+F_{2}\left(\theta_{t} L_{t}, K_{t}\right) K_{t}-K_{t+1}+(1-\delta) K_{t}\right)\right] .
$$

The $K_{t+1}$ inside the parentheses cancels, so that we can divide both sides of (37) by $K_{t}$, leaving

$$
\frac{C_{t}}{\mu_{t} C_{t-1}}=E_{t}\left[m r s_{t+1} \frac{C_{t+1}}{\mu_{t+1} C_{t}}\left(F_{2}\left(\theta_{t} L_{t}, K_{t}\right)+(1-\delta)\right)\right] .
$$

Finally, we substitute the definition of $m r s_{t+1}$ into (38) and collect terms, obtaining

$$
\frac{C_{t}\left(C_{t}\right)^{-\gamma}}{\mu_{t} C_{t-1}}=\beta E_{t}\left[\frac{C_{t+1}\left(C_{t+1}\right)^{-\gamma}}{\mu_{t+1} C_{t}}\left(F_{2}\left(\theta_{t} L_{t}, K_{t}\right)+(1-\delta)\right)\right] .
$$

Equation (39) is a function of $K_{t}, C_{t}$ and exogenous variables. To obtain this equation, we have used all the conditions for equilibrium except the resource constraint. This goods market equilibrium condition yields the second equation in the two-equation system that is used to solve for equilibrium:

$$
C_{t}=F\left(\theta_{t} L_{t}, K_{t}\right)-K_{t+1}+(1-\delta) K_{t}
$$

(39) and (40) are identical to (14) and (15). Thus, the stock market economy is represented by the same set of stochastic difference equations as the used capital goods economy. 


\section{References}

Abel, Andrew, (1985), "Dynamic Behavior of Capital Accumulation in a Cash-in-Advance Model," Journal of Monetary Economics, 16, 55-71.

Altuğ, Sumru, (1993), "Time-to-Build, Delivery Lags, and the Equilibrium Pricing of Capital Goods," Journal of Money, Credit, and Banking, 25, 301-319.

Altuğ, Sumru, and Labadie, Pamela, (1994), Dynamic Choice and Asset Markets, San Diego: Academic Press.

Boyle, Glenn W., (1990), "Money Demand and the Stock Market in a General Equilibrium Model with Variable Velocity," Journal of Political Economy 98, 1039-53.

Boyle, Glenn W. and James D. Peterson, (1995), "Monetary Policy, Aggregate Uncertainty and the Stock Market," Journal of Money Credit and Banking 27, 570-582.

Boyle, Glenn W. and Leslie Young, (1988), "Asset Prices, and Money: A General Equilibrium, Rational Expectations Model," The American Economic Review 78, 24-45.

Brock, William A. and Leonard Mirman, (1972), "Optimal Economic Growth and Uncertainty: The Discounted Case," Journal of Economic Theory 4, 479-513.

Campbell, John Y., (1994), "Inspecting the Mechanism: An Analytical Approach to the Stochastic Growth Model," Journal of Monetary Economics 33, 463-506.

Carlstrom, Charles T., and Timothy S. Fuerst, "Interest Rate Rules vs. Money Growth Rules: A Welfare Comparison in a Cash-in-Advance Economy," Journal of Monetary Economics, $36,245-246$.

Chami, Ralph, Thomas F. Cosimano and Connel Fullenkamp, (1999), "Ownership of Capital in Monetary Economies and the Inflation Tax on Equity," working paper International Monetary Fund.

Christiano, Lawrence J., (1990), "Solving the Stochastic Growth Model by Linear-Quadratic Approximation and by Value-Function Iteration," Journal of Business and Economic Statistics 8, 23-26. 
Cochrane, John H., (1991), "Production-Based Asset Pricing and The Link Between Stock Returns and Economic Fluctuations," The Journal of Finance 46, 207-34.

Coleman, Wilbur J., (1996b), "Functional Equivalence Between Transaction Based Models of Money and Distorted Real Economies," working paper, Duke University.

Cooley, Thomas F., (1995), Frontiers of Business Cycle Research, Princeton, NJ: Princeton University Press.

Cooley, Thomas F., and Gary D. Hansen, (1989), "The Inflation Tax in Real Business Cycle Models," American Economic Review, 79, 733-48.

Cooley, Thomas F., and Gary D. Hansen, (1995), "Money and the Business Cycle," in Frontiers of Business Cycle Research, edited by Thomas F. Cooley, Princeton, NJ: Princeton University Press.

Diba, Behzad T. and Herschel I. Grossman, "The Theory of Rational Bubbles in Stock Prices,' The Economic Journal, September 1988, 98, 746-754.

Giovannini, Alberto, and Pamela Labadie, (1991), "Asset Prices and Interest Rates in Cashin-Advance Models," Journal of Political Economy, 99, 1215-51.

Hodrick, Robert J., Narayana Kocherlakota and Deborah Lucas, (1991), "The Variability of Velocity in Cash-in-Advance Models," Journal of Political Economy 99, 358-84.

King, Robert G., Charles I. Plosser and Sergio T. Rebelo, (1988), "Production, Growth and Business Cycles I; The Basic Neoclassical Model," Journal of Monetary Economics 21, $195-232$.

Labadie, Pamela, (1989), "Stochastic Inflation and the Equity Premium," Journal of Monetary Economics 24, 277-98.

Lucas Robert E. Jr., (1982), "Interest Rates and Currency Prices in a Two-Country World." Journal of Monetary Economics 10, 335-359.

Lucas Robert E. Jr. and Nancy L. Stokey, (1987), "Money and Interest in a Cash-in-Advance Economy," Econometrica 55, 491-513.

Mackinnon, Keith, (1987), "More on the Inflation Tax and the Value of Equity," Canadian Journal of Economics 20, 823-831. 
Marshall, David A., (1992), "Inflation and Asset Returns in a Monetary Economy," The Journal of Finance 47, 1315-42.

Mirman, Leonard J. and Itzhak Zilcha, (1975), "On Optimal Growth Under Uncertainty," Journal of Economic Theory 11, 329-345.

Modigliani, F. and M. H. Miller, (1958), "The Cost of Capital, Corporate Finance, and the Theory of Investment," The American Economic Review 48, 261-297.

Patelis, Alex D., (1997), "Stock Return Predictability and The Role of Monetary Policy," The Journal of Finance 52, 1951-1972.

Restoy, Fernando, and G. Michael Rockinger, (1994), "On Stock Market Returns and Returns to Investment," The Journal of Finance 49, 543-556.

Sargent, Thomas J., (1987), Dynamic Macroeconomic Theory, Cambridge: Harvard University Press.

Sharpe, Steven A., (1999), "Stock Prices, Expected Returns, and Inflation," Finance and Economics Discussion Series (FEDS) Paper 1999-2, Federal Reserve Board of Governors.

Svensson, Lars E.O., (1985), "Money and Asset Pricing in a Cash-in-Advance Economy," Journal of Political Economy 95, 919-945.

Stockman, A. (1981), “Anticipated Inflation and the Capital Stock in a Cash-in-Advance Economy," Journal of Monetary Economics 8, 387-393.

Stokey, Nancy L. and Robert E. Lucas, Jr., with Edward C. Prescott, (1989), Recursive Methods in Economic Dynamics, Cambridge: Harvard University Press.

Thorbecke, Willem, (1997), "On Stock Market Returns and Monetary Policy," The Journal of Finance 52, 635-654. 


\section{Referee's Guide}

\section{.1 Consumer's Problem under CIA and household ownership of capital}

The value function of the consumer is given by

$$
\begin{gathered}
V\left(\mu_{t}, \theta_{t}, K_{t}, \frac{\mathcal{W}_{t}+Q_{t} k_{t}^{s}}{P_{t}}\right)=\max \left[\frac{C_{t}^{1-\gamma}}{1-\gamma}+\eta_{t}\left(\frac{M_{t}^{p}}{P_{t}}-C_{t}\right)+\lambda_{t}\left(\frac{\mathcal{W}_{t}+Q_{t} k_{t}^{s}}{P_{t}}-\frac{Q_{t} k_{t}^{d}}{P_{t}}-\frac{M_{t}^{p}}{P_{t}}-\mathcal{T}_{t}\right)\right. \\
\beta E_{t}\left[\frac{C_{t+1}^{1-\gamma}}{1-\gamma}+\eta_{t+1}\left(\frac{M_{t+1}^{p}}{P_{t+1}}-C_{t+1}\right)+\lambda_{t+1}\left(\frac{\mathcal{W}_{t+1}+Q_{t+1} k_{t+1}^{s}}{P_{t+1}}-\frac{Q_{t+1} k_{t+1}^{d}}{P_{t+1}}-\frac{M_{t+1}^{p}}{P_{t+1}}-\mathcal{T}_{t+1}\right)\right] \\
+\beta^{2} E_{t}\left[V\left(\mu_{t+2}, \theta_{t+2}, K_{t+2}, \frac{\mathcal{W}_{t+2}+Q_{t+2} k_{t+2}^{s}}{P_{t+2}}\right)\right] .
\end{gathered}
$$

Here $\lambda_{t}$ and $\eta_{t}$ are the Lagrange multipliers for the constraints (8) and (9), respectively.

The consumer chooses money balances in period $t$ according to the rule

$$
\eta_{t}=\lambda_{t}-\beta E_{t}\left[\lambda_{t+1} \frac{P_{t}}{P_{t+1}}\right]
$$

If we recognize that $\mathcal{W}_{t+1}+Q_{t+1} k_{t+1}^{s}$ evolves according to (10), then the consumer chooses used capital to satisfy the condition

$$
\lambda_{t} \frac{Q_{t}}{P_{t}}=\beta E_{t}\left[\lambda_{t+1}\left(\frac{P_{t} F_{2}\left(\theta_{t} L_{t}, K_{t}\right)}{P_{t+1}}+\frac{Q_{t+1}}{P_{t+1}}(1-\delta)\right)\right] .
$$

In the second session the consumer chooses consumption to satisfy the consumer's optimal condition

$$
C_{t}^{-\gamma}=\eta_{t}+\beta E_{t}\left[\lambda_{t+1} \frac{P_{t}}{P_{t+1}}\right]
$$

If we recognize that $\mathcal{W}_{t+2}+Q_{t+2} k_{t+2}^{s}$ evolves according to (10) updated one period when $k_{t+1}^{d}=k_{t+1}^{s}=(1-\delta) k_{t}^{d}+I_{t}$, then the consumer chooses investment to satisfy the condition

$$
\beta E_{t}\left[\lambda_{t+1} \frac{P_{t}}{P_{t+1}}\right]=\beta^{2} E_{t}\left[\frac{\partial V}{\partial\left(\frac{\mathcal{W}_{t+2}+Q_{t+2} k_{t+2}^{s}}{P_{t+2}}\right)}\left(\frac{P_{t+1} F_{2}\left(\theta_{t+1} L_{t+1}, K_{t+1}\right)}{P_{t+2}}+\frac{Q_{t+2}}{P_{t+2}}(1-\delta)\right)\right] .
$$

In making each of these decisions the consumer uses the expected marginal value of wealth. Using the Mirman-Zilcha (1975) condition,${ }^{25}$ the expected marginal value of wealth is given by

$$
\frac{\partial V}{\partial\left(\frac{\mathcal{W}_{t}+Q_{t} k_{t}^{s}}{P_{t}}\right)}=\lambda_{t}
$$

\footnotetext{
${ }^{25}$ See Stokey and Lucas with Prescott (1989, pp.266-267).
} 
Furthermore, the above optimal conditions for money and consumption imply that

$$
C_{t}^{-\gamma}=\frac{\partial V}{\partial\left(\frac{\mathcal{W}_{t}+Q_{t} k_{t}^{s}}{P_{t}}\right)}=\lambda_{t}
$$

Consequently, we can substitute the marginal utility of consumption for the marginal utility of wealth in the consumer's optimal decisions for used and new capital goods to yield

$$
\frac{Q_{t}}{P_{t}}=\beta E_{t}\left[\left(\frac{C_{t+1}}{C_{t}}\right)^{-\gamma}\left(\frac{P_{t} F_{2}\left(\theta_{t} L_{t}, K_{t}\right)}{P_{t+1}}+\frac{Q_{t+1}}{P_{t+1}}(1-\delta)\right)\right]
$$

and

$\beta E_{t}\left[\left(\frac{C_{t+1}}{C_{t}}\right)^{-\gamma} \frac{P_{t}}{P_{t+1}}\right]=\beta^{2} E_{t}\left[\left(\frac{C_{t+1}}{C_{t}}\right)^{-\gamma}\left(\frac{C_{t+2}}{C_{t+1}}\right)^{-\gamma}\left(\frac{P_{t+1} F_{2}\left(\theta_{t+1} L_{t+1}, K_{t+1}\right)}{P_{t+2}}+\frac{Q_{t+2}}{P_{t+2}}(1-\delta)\right)\right]$,

which correspond to equations (12) and (13), respectively.

\section{.2 Consumer's Problem under CIA and stock ownership}

The consumer's problem is a dynamic programming problem with the value function given by

$$
\begin{aligned}
& V\left(\mu_{t}, \theta_{t}, \frac{W_{t}}{P_{t}}\right)=\max \left[\frac{C_{t}^{1-\gamma}}{1-\gamma}+\eta_{t}\left(\frac{M_{t}^{p}}{P_{t}}-C_{t}\right)+\right. \\
& \left.\lambda_{t}\left(\frac{W_{t}}{P_{t}}-\frac{P_{t}^{s} S_{t}}{P_{t}}-\frac{M_{t}^{p}}{P_{t}}-\mathcal{T}_{t}\right)+\beta E_{t}\left[V\left(\mu_{t+1}, \theta_{t+1}, \frac{W_{t+1}}{P_{t+1}}\right)\right]\right] .
\end{aligned}
$$

Here $\lambda_{t}$ and $\eta_{t}$ are the Lagrange multipliers for the constraints (9) and (19), respectively.

The consumer chooses money balances in period $t$ according to the rule

$$
\eta_{t}=\lambda_{t}-\beta E_{t}\left[\frac{\partial V}{\partial\left(\frac{W_{t+1}}{P_{t+1}}\right)} \frac{P_{t}}{P_{t+1}} .\right]
$$

The consumer chooses stocks to satisfy the condition

$$
\lambda_{t}=\beta E_{t}\left[\frac{\partial V}{\partial\left(\frac{W_{t+1}}{P_{t+1}}\right)} R_{t+1}^{s} \frac{P_{t}}{P_{t+1}}\right] .
$$

In the second session the consumer chooses consumption to satisfy the consumer's optimal condition 


$$
C_{t}^{-\gamma}=\eta_{t}+\beta E_{t}\left[\frac{\partial V}{\partial\left(\frac{W_{t+1}}{P_{t+1}}\right)} \frac{P_{t}}{P_{t+1}}\right] .
$$

In making each of these decisions the consumer uses the expected marginal value of wealth. Using the Mirman-Zilcha (1975) condition, ${ }^{26}$ the expected marginal value of wealth is given by

$$
\frac{\partial V}{\partial\left(\frac{W_{t}}{P_{t}}\right)}=\lambda_{t}
$$

Furthermore, the above optimal conditions for money and consumption imply that

$$
C_{t}^{-\gamma}=\frac{\partial V}{\partial\left(\frac{W_{t}}{P_{t}}\right)}=\lambda_{t} .
$$

Substituting the marginal utility of consumption into the optimal condition for stocks

$$
1=\beta E_{t}\left[\left(\frac{C_{t+1}}{C_{t}}\right)^{-\gamma} \frac{P_{t}}{P_{t+1}} \frac{\left(P_{t+1}^{s}+D_{t}\right)}{P_{t}^{s}}\right] .
$$

The above condition corresponds to condition (22).

\footnotetext{
${ }^{26}$ See Stokey and Lucas with Prescott (1989, pp.266-267).
} 
Response of Value of the Firm to Monetary Shock

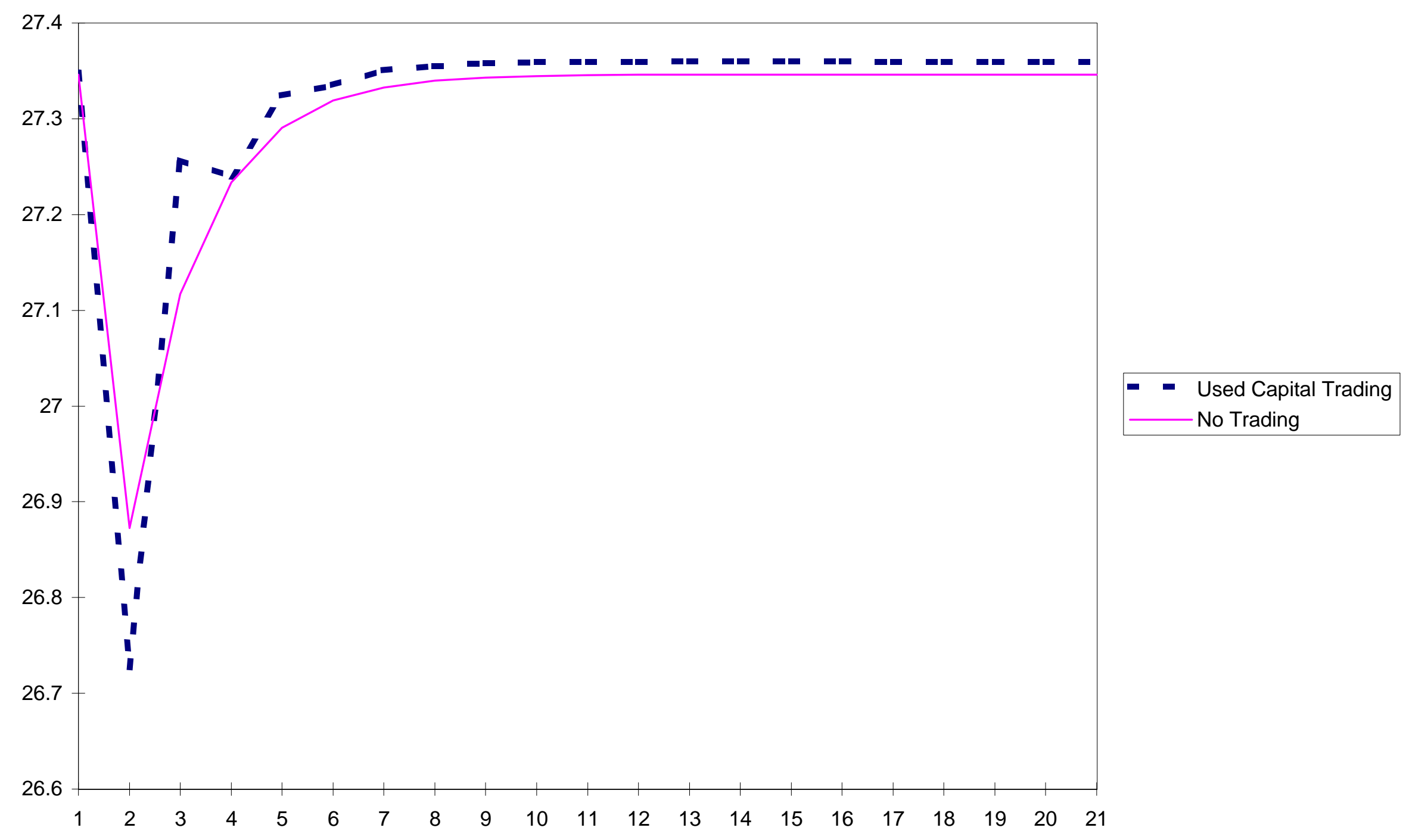


Chart 1

Timing of Activities, Decisions, Information and Payments

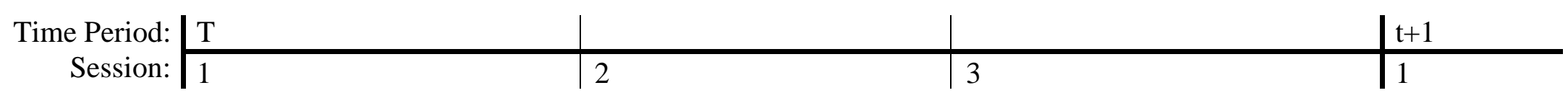

\begin{tabular}{|c|c|c|c|}
\hline Activities: & $\begin{array}{l}\text { Asset Market Clears } \\
\text { Factor Markets Clear } \\
\text { Production }\end{array}$ & Goods Market Clears & Settlement \\
\hline $\begin{array}{l}\text { Decisions: } \\
\text { (HH refers to } \\
\text { Household.) }\end{array}$ & $\begin{array}{l}\text { HH: Sell } k_{t}^{\mathrm{s}}=(1-\delta) k_{t-1}^{\mathrm{d}}+\mathrm{I}_{\mathrm{t}-1} \\
\text { HH: Purchase } \mathrm{k}_{\mathrm{t}}^{\mathrm{d}}, \mathrm{M}_{\mathrm{t}}^{\mathrm{p}} \\
\mathrm{HH}: \text { Supply } \mathrm{L}_{\mathrm{t}}^{\mathrm{s}} \\
\text { Firm: Produce } \mathrm{Y}_{\mathrm{t}}\end{array}$ & $\mathrm{HH}$ : Purchase $\mathrm{C}_{\mathrm{t}}, \mathrm{I}_{\mathrm{t}}$, & \\
\hline Information Revealed: & $\mu_{\mathrm{t}}, \theta_{\mathrm{t}}, \mathrm{Q}_{\mathrm{t}}$ & $\mathrm{P}_{\mathrm{t}}$ & \\
\hline Household Receipts: & $-P_{t} T_{t}=M_{t}-M_{t-1}$ & $-\mathrm{P}_{\mathrm{t}} \mathrm{C}_{\mathrm{t}}$ & $\mathrm{W}_{\mathrm{t}} \mathrm{L}_{\mathrm{t}}^{\mathrm{s}}, \mathrm{R}_{\mathrm{t}} \mathrm{k}_{\mathrm{t}}^{\mathrm{d}},-\mathrm{P}_{\mathrm{t}} \mathrm{I}_{\mathrm{t}}$ \\
\hline Total Wealth: & $\mathrm{Q}_{\mathrm{t}} \mathrm{k}_{\mathrm{t}}^{\mathrm{s}}+W_{\mathrm{t}}$ & $\mathrm{Q}_{\mathrm{t}} \mathrm{k}_{\mathrm{t}}^{\mathrm{d}}+\mathrm{M}_{\mathrm{t}}^{\mathrm{p}}$ & $\begin{array}{l}\mathrm{k}_{\mathrm{t}+1}^{\mathrm{s}}=(1-\delta) \mathrm{k}_{\mathrm{t}}^{\mathrm{d}}+\mathrm{I}_{\mathrm{t}} \\
W_{\mathrm{t}+1}=\mathrm{M}_{\mathrm{t}}^{\mathrm{p}} \mathrm{P}_{\mathrm{t}} \mathrm{C}_{\mathrm{t}}-\mathrm{P}_{\mathrm{t}} \mathrm{I}_{\mathrm{t}}+\mathrm{W}_{\mathrm{t}} \mathrm{L}_{\mathrm{t}}^{\mathrm{s}}+\mathrm{R}_{\mathrm{t}} \mathrm{k}_{\mathrm{t}}^{\mathrm{d}}\end{array}$ \\
\hline
\end{tabular}

